\title{
Some Thoughts on the Virtue of Education
}

\author{
Xi Fang \\ School of Philosophy and politics Law \\ Yunnan Normal University, Kunming 650500, China; \\ fangxi1982@126.com
}

\author{
Mengwen Pan \\ School of Yunnan language and culture \\ Yunnan Normal University \\ Kunming 650500, China; \\ 77071393@qq.com
}

\begin{abstract}
The purpose of this paper is to systematically consider the issue of moral education, so as to teach the majority of colleagues and experts and scholars. Firstly, this article through a comprehensive understanding of the connotation of virtue, and then in-depth analysis of the concept of moral education, and finally deeply thinking about how to do a good job in moral education. It is concluded that moral education refers to the inherent human conscience, tolerance, kindness and other personality traits and psychological quality, if you want to effectively improve the effectiveness of moral education, strengthen moral education is imperative. The uniqueness of this article lies in the combination of contemporary society's "moral crisis", to explore how to contribute to the realization of the ultimate goal of moral education, and to cultivate moral and intellectual people.
\end{abstract}

Keywords-Virtue ; Virtue education; Thought

\section{INTRODUCTION}

It is well known that China has achieved rapid development since the reform and opening up and achieved enduring achievements and fruitful achievements in politics, economy, culture, education and so on. However, the moral level has not been very good and very quickly promoted, the effectiveness of contemporary moral education has been an indisputable fact and all kinds of immoral phenomena happen frequently. Chinese people who live in the contemporary era generally feel that the moral situation in China is very bad, even worrying. As a warning for the future, people began to examine the relationship between morality and the level of social and economic development, while profoundly recognizing the importance of virtue education. The reason is that China is in a period of social transformation with profound changes in values, and it is difficult to avoid some confusion in the state of morality." Once the society has undergone dramatic changes, the moral behavior problems of any society will also appear sharply, and the change of behavior patterns will be much slower in a relatively stable society." The moral education in our country does not adjust well with the violent changes of the social reform, comrade Deng xiaoping once concluded that education was the biggest failure in the reform and opening up, and the failure of morality education was a particularly crucial factor. It's just like since 1990s, the scientific research of Chinese ethics circle has been centered on the theme of "ruling by virtue", "moral crisis" and "moral reconstruction". The 18th national congress of the communist party of China (CPC) made it clear

[Foundation item] This paper is a periodical achievement of the National Social Science Fund youth project "The debate and significance of the contemporary Western Virtue Ethics and normative ethics" (project number: 17CZX054) that "the basic task of making the people of lide as education", president Xi Jinping further pointed out and emphasized that "adhere to moral education" and so on, such as to show the importance of moral education. Obviously, if we want to effectively resolve the "moral crisis" in the contemporary society, it is imperative to strengthen the moral education.

\section{WHAT IS VIRTUE}

Virtue, it is a timeless complex ethics category. No matter Chinese Kong Meng, ancient Greek three sages, or today has been divided into independent subject to its argument, unable to agree on which is right. Aristotle points out that "Virtue" is the "praiseworthy quality", and said "the virtue of man is the quality that makes a man good and enables him to perform his activities well." [1] Macintyre has made a functionalist definition of virtue in his most important work---After virtue: A Study to Moral Theory. that "virtue must be understood as such a quality: not only to maintain practice, to gain the inherent benefits of practice, but also to overcome the harm, danger, temptation and laxity we have encountered, it supports us in the pursuit of the good of the related types, and will enrich us with the growing awareness of self and the understanding of good."[2] Or, as Williams points out: "Virtue is an immanent nature of action, desire and feeling. But it is a rational nature, it involves the use of the actor to judgment or practical reason, so it is not just a habit. "[3] As Professor Jiang Chang said, "Virtue is the fundamental requirement that man uses reason or wisdom to seek the better nature of survival, and in order to live better to point to the cultivation, the effect of psychological setting on human activity, and make human activities and their subjects a good quality, that is, the quality of morality." It has the five characteristics of directivity, intentionality, multidimensional, unity, stability and universality. [4] So what is the meaning of "Virtue" in moral ethics, and how should we define "Virtue" ?

Further, virtue ethics is the core of morality, it pays attention to the virtues and the happy life of people, and rule ethics regards the establishment of moral rules as its purpose, they believe that the rules can provide rational guidance for people's moral behavior. However, in real life, "the moral philosophers with complex rules are not better than doctors, police and other professionals in solving practical problems." In the view of virtue ethics, rule ethics stipulate human moral behavior as moral rule, this is a simple mechanized understanding of human moral life. Because a person's advice to solve the dilemma is reasonable or not, it ultimately depends on its moral character, not the rule system. If a person 
already has a noble moral character and is keen and compassionate, she doesn't need regular guidance and help to make the right behavior, the rules are not enough and necessary for moral correctness. A man of virtue is a person who does not feel a moral discipline and is binding on himself, he is a free man to have whatever is desired is not more than a moment. Or like Pichemusuo said: "In moral life, people consider most, often not continue to stick to the principle or rules, preferring a credible character, good sense of morality and the basis of the true feelings of acting "In virtue ethics, the basis of morality is back to the subject of behavior. The meaning of "Virtue" shows that morality is not just public rules, it also includes the moral character and moral ideal that the individual accepts voluntarily, and the moral emotion derived from the individual. The gist of "Virtue" rejects "rules" is: it should be based on "the actor" and not just the behavior to do a moral "reduction" to the rule ethics; it should be regarded as a unity of human nature, thus providing a premoral evaluation basis for behavior evaluation. [5] As a result, we can conclude that "virtue" is the category of human nature from the angle of good and evil, A broad sense of virtue refers to morality, a narrow sense of virtue refers to a good quality. That is, virtue is actually a neutral word; it is the state of the comprehensive and stable characteristic that the main body shows in the long-term and a series of moral behaviors. [6]

\section{WHAT IS THE VIRTUE EDUCATION}

Through the above statement, if we approve of "virtue" is the basis of "gain", so the "virtue" is actually reflected as a natural person, use of internal and external factors, to observe, understand and conscientiously follow the natural laws, and from the results of the practice of obeying the laws of nature and the positive meaning of obeying the social law, then it focuses on the "socialization" of the rules of society. From this, the virtue education is intended to make the body/physiology as the basic existence form, gradually transcending the existence of physical/physiological, and becoming the aggregation of the existence of meaning. In this sense, the essence of virtue education is to reduce the proportion of the existence of the biological nature to the human nature - the social dual existence, to promote the social existence of human beings in the proportion of human being's holistic existence, it makes people more and more out of "physical", and converge to "human nature". On the value of its twodimensional orientation: At the macro level of the collective, it is a necessary part of national governance under the framework of nationalization, institutionalization and communalization of education, Beyond the rules of ethics, virtue ethics in public oriented, to make collective such as forms of social progress as a whole, this is the social standard of moral education; At the microcosmic level of the individual, it is the fundamental way to lead and educate individuals through the virtues required by the present and future progressive societies to enable individuals to be happy, this is the personal standard of virtue education. The fundamental carrier of moral education is the individual, society is the existence of collective form, individual and collective dialectical unity in practice or that practicality is the fundamental characteristic of human existence, and this fundamental feature determines the unity of the value of the two-dimensional orientation of the moral education to the social practice.

Just as its name implies, we can define the moral education as a social practice that aims to cultivate the morality of human beings and improve their moral level or state. Of course, moral education, as a concept, also has a broad and narrow sense. The broad sense of virtue education refers to all social practice which helps to enhance the virtues of human beings, the narrow sense of virtue education refers to the moral education in school education. It is not optimistic that although virtue education is related to social order and well-being at a macro level, it is related to individual happiness on the micro level, but in reality, it persists in material and even physical enjoyment, but it is far away from the more essential spiritual existence. This plight of virtue education has attracted many scholars' attention in recent years. Li Yongheng attributed it to the double predicament of theory and practice. Theoretically, due to the inherent theoretical dilemma of the "universal rationalism" of modernity, namely the self-realization of moral ontology, the contract of moral relations, the intellectualization of moral content and "the colonization of moral life"; in practice, it is the spiritual degradation of moral education, the absence of moral subjects, and the transmission of knowledge in the process of moral education. [7] Zhao Xiuwen described it as a deviation from the "advertised morality" and "abandoned morality", and the difference between "enthusiastic slogans" and "lonely practices" in school education, the game of moral education itself is "political", "educational" and "moral".[8] Xian Yu Lejiao described it as "the pursuit of utensils or systems". "the tendency of attaching importance to the skill of making a living despises the development of the mind and attaching importance to instrumental rationality and to disregard value rationality." [9] Obviously, virtue education has not only been in an embarrassing situation, but also its value is inevitable. In order to effectively guarantee human transformation of natural achievements and serve the realization of the fundamental value of human well-being, human society must not be divorced from virtue education, and virtue education is imminent.

\section{HOW TO DO A GOOD JOB OF VIRTUE EDUCATION}

In summary, on the one hand, moral education should adhere to the overall unity of the main body of education. The underage "educated" has the guardian, namely the main body of family education, whose guardian has the obligation to implement the moral education; the teachers and administrators of their school, namely the main body of education, have the duty to implement the moral education; the social managers within the scope of their activities, such as the traffic police, the supermarket operator, are the main body of social education, they also have the right to use social rules to implement moral education. In fact, although it is nominally "underage educated", it is still the subject of its own education--the learner. That is sticking to the overall unity of education subjects is to insist on the unified presence of family education, school education, social education and selfeducation. On the other hand, from the practice of virtue education, we should go hand in hand and take into account 
the intellectual and non-intellectual factors in moral education. That is to say, the real movement of virtue is the cognitioninternalization-externalization and transformation process of the internal influence of the main body mechanism, which is exerted by the external environment. [10] I believe that the process from cognition to internalization and then to externalization is only one of the possible theories of theory, but not necessarily the only form of the physical movement of virtue. If we admit that virtue is irrational from the ontological point of view, it is not irrational or the components of nonintelligence, so the realistic movement of virtue, that is, the moral education in essence, may also be the process from experience to behavior to internalization and externalization. In one word, in the process of carrying out virtue education, we should not only recognize the basic role of virtue cognition, but also not ignore the value of virtue experience.

In other words, Confucius's "benevolence" thought, Socrates's "virtue is knowledge" and Platon's "virtue and justice theory", all this provide inspiration for our virtue education today. However, virtue is rooted in the existence of the body of physical life, which is fundamentally an individual. As individual people, and the existence and development of the human society as a collective, they all have their social historicity. The enrichment and promotion of the virtue of the individual, of course, will certainly contribute to the enrichment and promotion of the moral character of the society as a whole; on the other hand, the enrichment and promotion of the virtue of individual as the individual needs to be born and nourished as the virtue of the collective society. It is the relationship between the egg and the chicken in theory. We should recognize the social and historical nature of virtue and virtue education, adhere to the consideration of the "Recent Development Zone" from the development of the present social virtue as a possible interval for the development of individual virtue, we can neither blindly apply the virtues of the ancient society nor use the virtues of the higher social development stage to regulate all the members of the society. This may not only imprison people's thought and creativity, but also frustrate the enthusiasm of the people's selfdevelopment, and reduce the prestige of the psychological level of the moral education of the members of the society. In the present, what is the extension of the virtue of the new era? From the perspective of state governance, the 24 word socialist core values are the outcome of concrete practice that echoes this topic; it takes good account of the social historicity of virtue in socialist countries.

\section{CONCLUSION}

Virtue education is based on virtue ethics, which is not only a moral emotion or a moral reason, but also a moral practice, it pays attention to the inner qualities of the human being, "taking the overall generation of individual moral personality and the highly disciplined behavior of individual morality as the core content, taking the lofty nature of individual moral spirit and the perfection of individual moral behavior as the core goal",[11] emphasizing the cultivation of individual deep, stable moral tendencies and moral abilities, through educate individual with following moral norms, guide individuals to internalize their identity in moral practice, and on the basis of identity, internalizing the mind and externalizing into action can make moral behavior spontaneously, which helps to achieve the ultimate goal of moral education and truly cultivate moral and intellectual people. Therefore, it should be added that doing good virtue education should pay special attention to the virtues of the virtue education system. Specifically, the system is the premise of moral freedom, is the tool and way to form a stable social order, to provide protection for the moral construction, the development of the system for moral education rules, but also require the system itself is reasonable, virtue, justice and social justice. That is, a reasonable institutional norm establishes a series of norms in the form of the nature of human nature in the form of institutionalization, give individual behavior the necessary external constraints, tell people what to / can do, should not / can't do, and provide sufficient explanation, so as to improve individual moral consciousness, strengthen individual moral will, help individuals establish correct values and improve individual moral level. The system of virtue is the inner basis for obtaining the rationality of existence, only by carrying and showing the rules and regulations of a certain moral spirit can we win the public recognition. The system of virtue will help internal moral and external regulations to achieve "coalesce", instead of imposing external values on an upbringing soul. The system of justice is prior to individual goodness, the system of justice is prior to individual goodness, and the virtue system is a big problem with more universal, global and fundamental than individual virtue. In sum, the system of highlighting virtue can effectively nourish the development of individual morality. When carrying out virtue education, we must give full play to the restraint of system, transform the external moral norm into individual moral character, and cultivate person with virtue through virtue system.

[About the author] Xi Fang (1982- ) Male, Tongshan Hubei people, associate Professor of School of philosophy and politics law, Yunnan Normal University, master supervisor, doctor of philosophy, mainly engaged in Western Ethics Research. Mengwen Pan (1990- ), Female, Yibin Sichuan people, corresponding author teacher of School of Yunnan language and culture Yunnan Normal University, doctoral candidates in Zhongnan University of Economics and Law, Mainly engaged in the study of Marx's Ethics.

\section{REFERENCES}

[1] Aristotle, “Nicomachean Ethics”, Liao ShenBai's Translation,Shanghai: The Commercial Press, 2003, pp.6.

[2] Macintyre,“After virtue: A Study to Moral Theory”, Gong Qun, Dai Yangyi's Translation Beijing: China Social Sciences Press,1995,pp.277.

[3] Bernard Wi11iams, "Ethics and the Limits of Philosophy" London: Fontana Press,1985, pp.36.

[4] Jiang Chang, “virtue theory" Beijing: People's publishing house, 2011,pp.30-39.

[5] Fang Dezhi,“The rejuvenation of virtue and moral education--On the Enlightenment of Aristotle's theory of virtue to the rejuvenation of virtue ethics”, Research on ethics,vol.3,2010,pp.6.

[6] Wang Guoyin,“The study about virtue ethics”, Doctoral dissertations of Soochow University,vol.6,2006. 
[7] Li Yongheng, "The predicament and the way out of modern moral education”, Master's degree thesis of Soochow University, vol. 6, 2006.

[8] Zhao Xiuwen, “Analysis of the current plight of moral education in China”, Chinese Education Journal,vol8,2009.

[9] XianYu Lejiao, "Whether morality can be virtual -- a moral study of contemporary youth network behavior” Journal of Guangdong Polytechnic Normal University,vol.3,2012.
[10] Wang Guoyin, “The study about virtue ethics”, Doctoral dissertations of Soochow University,vol.6,2006.

[11] Tang hong, "Moral education and virtue education--from disagreement to communion”, Research on Ideological Education, vol.3, 2011. 